\title{
TIEMPO, FUERZA Y ASCENSO EN EL REALISMO INTENSIVO DEL DR. ATL. PROPOSICIONES TEORICO-POETICAS PARA UNA NUEVA INTERPRETACIÓN DE SU PINTURA
}

\author{
Elia Espinosa López
}

\section{Historia de una decisión}

Hace ya casi ocho años inicié una larga investigación sobre el Dr. Atl. Tenía pensado dedicarme al estudio de su ideología política y escribir un libro sobre ella descuidando un poco, quizá, al paisajista. Pero la necesidad y el azar me llevaron forzosamente por otros rumbos y esa investigación, aunque ya bastante adelantada, quedó trunca.

Hace algún tiempo removí ese material por simple interés y vivamente motivada por las posibles maneras de escribir este artículo. Entre todos mis apuntes encontré citas estupendas como para armar un buen escrito sobre el pensamiento del vulcanólogo, el agitador, el gran comentarista de política que aún radiante por el vigor con el que sus críticas y opiniones están redactadas en sus escritos, es decepcionante por sus tendencias nazi-fascistas. También encontré información como para reflexionar y escribir sobre el paisajista y sus paisajes, realidad que se vio reforzada por la gran exposición de su obra llevada a cabo en enero-febrero de 1985.

Abordo aspectos del hacer de Atl que se han discutido y analizado repetidamente en polémicas y estudios a lo largo de los años. Entre ellos se encuentra el libro de Arturo Casado Navarro, Gerardo Murillo, El Dr. Atl. La semblanza El Dr. Atl paisajista, de Antonio Luna Arroyo, poco aguda por cierto, en donde se considera a Atl un personaje "pintoresco". Los artículos que forman el volumen El Dr. Atl. Conciencia y paisaje 1875/1964, redactados por críticos de artes plásticas, de literatura y filósofos como Jorge Alberto Manrique, Jorge Hernández Campos, Françoise Perus y Eli de Gortari, entre otros, o las mesas redondas y charlas que tuvieron lugar en el Palacio de Mineria durante diciembre y enero del mismo año, con motivo de la gran retrospectiva de su obra que, adelantémoslo, con todo y sus altibajos en cuanto al propio material pictórico seleccionado, fue uno de los eventos culturales más potentes en belleza, arrojo técnico y logros estéticos que se han llevado a cabo en los últimos quince meses en México. 
Mi abordamiento de su pintura no es solamente el de una crítica o historiadori del arte, sino también el de una espectadora abierta de par en par y admiradora, lo aclaro, de los elementos sustanciales de sus cuadros: el tiempo, la fuerza y la diversa intensidad que esta manifiesta como vector, o como lo que en música se llama tan hermosamente "crescendo", o aún como un todo que, a más no poder de potencia (perdón por la redundancia) determina y conduce imperativamente lo que acaece en las dimensiones de sus cuadros.

Por lo tanto, mi propósito no es ofrecer una visión formal y composicional de su obra, sino desarrollar algunos aspectos sobre y en torno a la evolución y orígenes del proceso de captación y manejo de fuerzas en sus cuadros y de su fisio-estética en relación al cuerpo como conglomerado de funciones y potencias desplazable y autónoma. ¿Cuáles son los orígenes, o posibles principios, de esas formas que parecen nunca teneri tranquilidad dentro de las superficies que pintó? ¿Cómo y cuánto intervino el cuerpo, como organismo vivo y como estructura motora no orgánica en esos principios?

He utilizado el análisis abierto -asî llamo al análisis que persigue la lógica del objeto analizado sin rechazar las "llamaradas" únicas e irrepetibles del sencillo sentimiento de las cosas- de las formas y el color en su obra, porque son los terrenos que, ya lo veremos, nos permiten encarar y adentrarnos en la magnífica coherencia que existió entre su vida y sus paisajes. Consideramos las formas y el color como una armonía que guarda todo un enigma vibratorio y de fuerzas magnéticas cromático-motrices que siempre tienen un centro convergente y divergente a la vez, parecido al punto de fuga en la perspectiva de la pintura renacentista italiana. Formas y color que nada tienen que ver con convencionalismos; allí todo es cuantificado con miras a una totalidad pictórica universalizante que cristaliza en la obra misma.

Hemos "personificado", como en la poesía, las funciones de los objetos y las interrelaciones que estos mantienen en su obra. La captación y el desarrollo poéticos de una realidad poseen características que pueden ayudar al crítico de arte. Una visión o imagen en la cabeza del poeta desboca todo un tropel de acontecimientos imaginarios que se unen a la imagen desencadenadora, borrando el sentido del tiempo y multiplicándose en la obra. Bachelard escribe al respecto: "... el acto poético no tiene pasado, al menos pasado próximo a lo largo del cual se podría se- 
guir su preparación y su acontecer... la imagen poética no es el eco de un pasado. Es más bien lo contrario: por el chispazo de una imagen, los ecos del pasado lejano resuenan y no se ve casi a qué profundidad esos ecos repercutirán o se extenderán..." Es por esto que el crítico no puede descartar el poder de su intuición, por "subjetiva", "parcial" o "no productiva" que le parezca, pues ella le va ofreciendo flamazos que pueden asociar más carnal y vivamente una idea con otra, una teoría con otra y a éstas con la obra misma que las propició Es más: la entrada poética a un mundo específico no es voluntaria, o casi nunca voluntaria. Se presenta o no se presenta. No es como el análisis lógico, que procede por división o disección del objeto por analizar y se desenvuelve a lo largo de una sucesión dividida en etapas que en lugar de sintetizar-desarrollar, desarrolla-sintetiza para llegar a la meta propuesta por el plan inicial del estudioso.

El crítico, que en muchos casos lleva un sobrio o intenso poeta dentro, debe forzosamente ayudarse tanto de los "raptos" de la tendencia poético-analítica como de la tendencia lógico-analítica-formal (desarrolladorasintetizadora).

Este ensayo es una visión funcional-poética-totalizante de los elementos pictóricos, quinésicos y composicionales de los paisajes del Dr. Atl, en estrecho casamiento con los parámetros biológicos y físicos que determinaron su existencia de trotamundos incans?ble. Creo que en la frontera entre esos dos terrenos, el de sus "maneras" de vivir y el de las "maneras" esenciales que determinan el ser de las obras, se encuentra parte de la argamasa para modelar nuevas ideas, hipótesis e imágenes destinadas a considerar más hondamente su riqueza bio-artística.

Lo que se eleva y lo que cae..

Para incursionar en el mundo pictórico de Atl, hay que tomar en cuenta dos de los grandes sentidos que rigen el movimiento de la vida: lo que va de abajo hacia arriba y lo que cae, lo que a pesar de la gravedad terrestre asciende, y lo que no puede escapar a su poder de atracción hacia su centro. Entre estos dos sentidos están implícitos todos los otros posibles: el del desplazamiento, el de lo que sube o baja en diagonal, el de lo

\footnotetext{
${ }^{1}$ Gastón Bachelard, La poétique de l'espace, Paris, PUF, 1981 (Quadrige, 24) pp. 1-2
} 
que se mueve trazando círculos que ascienden formando una espiral que se pierde en el espacio por tan grande que llega a ser su abertura, etc.

Tal como lo conocemos, o como nos permite conocerlo, un volcán, tema pictórico principal de Atl, es una masa colosal de piedra estática, aposentada en un para-siempre aparentemente final. Pero un día creció a una terrible velocidad, como crece una planta. Se fue formando de abajo hacia arriba al mismo tiempo que vomitaba sus substancias incandescentes. Un volcán no se renueva constantemente como las plantas o los tejidos de un animal en lo que a sus partes o componentes se refiere, pero posee, tanto como ellos, como la bóveda celeste, la capacidad de hacernos sentir la magnitud del infinito. Ahí continúa su potencia intensiva. Cualquier paisaje en tanto que obra o panorama natural, implica esos fenómenos de crecimiento, renovación y muerte independientemente de las intenciones de su autor o no autor, pero no todos los paisajes, como obras de arte tienen como objetivo principal la captación de fuerzas que respiran detrás de las formas y contornos que aparente y superficialmente vemos. A nivel macrocósmico, el paisaje como representación atrística posee la virtud de mostrar llanamente y sin más complicación que la de solo mirarlas, las diferencias de orden que la materia ha seguido para llegar a sus diversos grados de densidad, textura, pesos, colores. A nivel microscósmico, también tiene la virtud de implicar desde la más sutil organización matérica: membranas, jugos, savia, agua, arena, etc., hasta la roca más tenaz y solemne, nubes, flores, tierra, aire, frío, calor; gran potencia para dar una gama sutilísima de seres dentro de la sincronía visual forzosa del cuadro o el mural.

La obra de Atl captó y aprehendió esencialmente esos procesos y las fuerzas e intensidades que laten tras las formas y contornos aparentes, y esa aprehensión y el impulso motor de su cuerpo son los que dan origen tanto a sus formas magnificentes como al vertiginoso movimiento de las mismas y la dinámica estructural de sus paisajes, sobre todo los de los volcanes. Sus frases tan conocidas: "No nací pintor. Pero nací caminante. Y el caminar me ha conducido al amor por la naturaleza y el deseo de representarla" " nos dan la clave para penetrar su mundo. No podemos entender la obra de Atl si no tomamos en cuenta la realidad del cuerpo como unidad que encierra una diversidad en constante movimiento y como unidad con capacidad propia para desplazarse. Sus paisajes son cuerpopaisajes, paisajes de voluntad, unidades cuyo interior está en constante

${ }^{2}$ Dr. ATL, El paisaje (un ensayo), México, [s e.] 1933 p. 4 
cambio y locomoción. Esto no quiere decir que Atl pinte su cuerpo o lo retrate, sino que éste es el trampolín de donde salta su inquietud primera y el amor que confiesá sentir por la naturaleza, y está implícito en la dinámica de su obra. Era un caminante-pintor, no un pintor contemplativo solamente. De ahí que diera esta definición fisio-estética del paisaje: "Para un pintor, para el artista ... el paisaje es el titmo de ondas que la $\mathrm{Na}$ turaleza extiende, tal vez generosamente - lo cual nos hace pensar que Atl cree en una "bondad" de la naturaleza-, donde saturarnos el espíritu de excelsas sensaciones de belleza y de energía"." Seguramente Atl nunca salió en su coche a buscar un paisaje desde el punto de vista estético tradicional, es decir por sentimiento o porque un conjunto formal se "adaptara" a su mero gusto o le agradara simplemente, sino que siempre se dejó "flechar" por la intensidsd que se confundía, sin duda, a la gran euforia de su cuerpo.

El que camina es en el desplazamiento, en la locomoción. El que camina atraviesa el espacio, marca la tierra y su cuerpo en movimiento traza o "reproduce" el hilo y formas de su pensamiento, surgiendo así una correspondencia de formas entre espíritu y andar. Hay una diacronía y una sincronía simultáneas, además de un esfuerzo constante, y todavía más si su trayecto se lleva a cabo en la escalada. Nuestro pintor no sólo era caminante, también era alpinista y el oficio principal del alpinista, el andar, lo vive como escención y, por lo tanto, como la aceleración de intensidad de sus funciones orgánicas (circulación, trabajo muscular, transpiración) y de la velocidad de la receptividad de su pensamiento y su sensibilidad. El caminante vive el paisaje como enfrentamiento y fuga horizontales incesantes; el alpinista lo vive como ascención y fuga con un horizonte sumamente cambiante a su paso (no es lo mismo caminar a paisaje abierto, lo cual implica tener una constante visual frente a sí, que caminar ascendiendo un plano inclinado o pared vertical, lo cual impone una variación ininterrumpida del horizonte inmediato).

Tanto el caminante como el alpinista invisten de su cuerpo al paisaje, y si se trata de un caminante-alpinista-pintor, como Atl, hombre consciente de la luz, la intensidad y las formas — sea cual fuere el tipo de pinturase establece un "dar y recibir" entre paisaje y conciencia. Pero quien se impone finalmente en este enfrentamiento es el pintor, porque es el que se desplaza, cambia frecuentemente sus perspectivas, sufre la variación formal y sensitiva en esa relación paisaje-panorama que tiene frente

\footnotetext{
${ }^{3}$ Arturo Casado, Gerardo Murillo, El Dr. ATL, México, IIE, UNAM, 1984, p. 195.
} 
a sí, y la expansión y contracción de su corazón en juego con las fuerzas visuales, tectónicas y de texturas del paisaje.

Las formas agresivas y siempre en movimiento de los paisajes de Atl tienen su origen en esa simbiosis y en la aceptación, pero de tipo plástico amoroso: "yo nunca salgo 'a buscar un paisaje': siempre dejo que el paisaje me busque a mí, que se eche violentamente sobre mi sensibilidad ...". Por eso dedujimos que en Atl el cuerpo tiene un papel fundamental en el proceso de gestación de su pintura, lo cual no quiere decir que los elementos del paisaje como panorama no intervengan en este proceso. Recordemos que es un captador y tratador de fuerzas; no impone formas porque trabaja intensidades...

Contrariamente a Atl, nuestro José $\mathrm{Ma}$. Velasco es un pintor contemplativo y no de búsqueda como encuentro violento. Su pintura no refleja el resultado de un choque explosivo, casi sexual y amoroso con el paisaje, como el del jalisciense. Más que de aceptación activa su pintura es de respeto al horizonte. Velasco no se hubiera permitido ninguna alteración formal que proviniera de impulsos personales; parece actuar bajo el lems: "la naturaleza es más grande que sus propias entidades individuales, por lo tanto, el artista sólo debe reproducir su universo formal, sus colores y su belleza". Velasco no era caminante, ni pintor-caminante por una necesidad enloquecida de desplazar su cuerpo llevado por el gozo mismo del movimiento. Su cuerpo se desplazaba porque sin él no se puede ir al encuentro de panoramas, horizontes y nubes gigantescas. Pero el elemento que iba verdaderamente a la búsqueda del paisaje establecido, de la estampa casi, desplegando su mera esencia, su "opticidad", era el ojo, no el cuerpo y la mano.

En Velasco, el cuerpo y la mano estaban sujetos a los designios del ojo. Sus posibilidades motrices hacían más el papel de instrumento que de fuente autónoma de energía que comunica su potencia incluso morfológica, al nacimiento de la obra. La mano de Atl, contrariamente a la de Velasco, se desplazaba enérgicamente sobre las superficies que pintaba, comunicando su connivencia integral, y hasta simbiosis, con el resto del cuerpo. Ojo, mano y cuerpo eran en él una máquina de tres niveles.

Los ojos de Velasco se deslizaban sobre un conjunto de cuyos elementos había que captar sólo las formas, colores, el aire y la grandiosa luz como alucinaciones afluyentes a una superficie, sin alterar nada. De ahí la calma enorme que emerge de sus obras, aunque pinte una tarde

${ }^{4}$ Dr. Atl, Gentes profanas en el convento, México, Ediciones Botas, 1950, p. 71. 
borrascosa. Así como en Atl el punto de partida es la fuerza ascendente y motriz, y un ojo intensificante más que representante, en Velasco es la calma horizontal que contempla el movimiento exterior sin añadir ninguna dinámica subjetiva que pueda alterar su equilibrio. E1 paisaje hace el amor a Velasco, mientras que Atl y el paisaje hacen el amor en una entrega mutua total y un intercambio de intensidades ascendentes; cuerpo y cuerpo con cuerpo produjeron sólo paisajes intensivos.

Tanta es la primacía del cuerpo y el movimiento de la pintura de Atl, que él nos habla de una "articulación interior", una "lógica de formas" que nace primero en el artista fisiológicamente hablando.

Atl deja que las formas lo tomen e incorporen a su red infinita de flujos dando así otro cúmulo, también infinito, de nuevas fuerzas a través de cuerpo, ojo y manos. De manera que, además del espacio, la realidad en la que se basa obviamente su pintura es el tiempo: tiempo del desplazamiento y tiempo de la consecución del esfuerzo supremo de sus acciones y vivencias. Sin el tiempo entre la salida y el encuentro - que es como un tiempo de cocimiento y sazón - esos paisajes no se hubieran gestado. El tiempo regirá su búsqueda de materiales, su técnica, sus "sentidos" incendiarios de la materia esparcida en el espacio. Su obra teórica nos lo confirma, aunque su pintura nos quiera hacer sentir que, claro está, el espacio es el punto de realización primera y última de la pintura, Luego entonces, los parámetros de los que surgiría su estética, una estética experimental -lo que nosotros llamaríamos su "estética" sólo por ayudarnos a visualizar figuritiva y conceptualmente los principios rectores de su arte, ya que el desarrollo y consecución de éste sobrepasan cualquier estética entendida como disciplina o conjunto de cánones- son dúos y trilogías de elementos que están subrayados por el tiempo del cuerpo y el del gozo, el gozo en sí y el de la creación:

$$
\begin{aligned}
& \text { espacio - esfuerzo - áscensión } \\
& \text { tiempo - fuerza - desplazamiento } \\
& \text { curva - lentitud - amplitud. }
\end{aligned}
$$

pero son el esfuerzo y el ascenso los que regulan el nacimiento y metabolismo de sus paisajes. Él mismo corrobora nuestras afirmaciones cuando escribe, excelsamente, que su propósito es "fijar la trayectoria de un nuevo esfuerzo a través de un nuevo espacio"." 
Atl me hace recordar a otro caminante pintor: Joseph Turner, el gran romántico inglés. Es válido objetar como en varios lectores sucederá, por qué emparento a Turner con Atl, si en el inglés no fue el amor por la forma y su dinámica y la línea lo que caracterizó su pintura, sobre todo al final de su vida, sino la explosión molecular que la materia incuba dentro de sus límites aparentes. Turner trasplantaba a la tela, dentro de un macrocosmos pictórico alucinante, el movimiento vertiginoso atómico y molecular que nuestros sentidos son incapaces de advertir. Pero su proceso es el mismo que el de Atl en varios aspectos: fue, como Atl, un caminante incansable, conoció grandes montañas europeas, sobre todo suizas, francesas e italianas. Aunque algunos de sus trabajos son "formales" - trazan las líneas de la arquitectura, los puentes, etcétera-, esas formas anuncian ya el estallido de sus famosas marinas con barcos en liamas que se incorporan violentamente a nubes y vientos tormentosos donde la intensidad variable de la luz es principio y fin. En lo caminante y en lo intensivo e intenso, Atl es hermano de Turner más que de José Ma. Velasco. En Turner los parámetros que acabamos de señalar nunca funcionan dentro de los límites de la forma, sino en el sin-límite de la luz y en un realismo imaginario que, fuera de sus paisajes de bosques, alcanzan niveles de un "crescendo" vertiginoso hacia la abstracción que nos comprueba que su autor fue un pintor de la materia no orgánica, de la materia sin peso y sin lugar establecidos; no era pintor de rocas, las que pintó parecen grandes masas ligeras elevándose entre las nubes, como se ve en obras como Las cumbres de Reichenbach, en el Paso, o aún más en su Erupción del Vesubio, de 1819, obra en la que a pesar del logro excelente de luminosidad de las masas ígneas que el volcán arroja, el logro plástico global estrictamente considerado es forzado y un tanto teatral, no alcanza la fluidez — por no decir "naturalidad"- de sus marinas o de algunos paisajes boscosos. La excesiva pastosidad con la que el color se extiende, lo denota; lo que cae no era la materia de trabajo esencial de Turner.

Dados los parámetros filosófico-poéticos en los que se mueve el pensamiento creador de Atl, y dada la naturaleza molecular vertiginosa, sumamente dinámica de los elementos de su pintura (cráteres, nubes, árboles, piedras, el espacio mismo como vehículo de vibraciones y de fuerzas magnéticas múltiples en juego con su voluntad imperiosa de aprehender, como hemos repetido tantas veces, las intensidades y luego las formas -porque ellas vienen de la idea y la sensación-) no había otro camino que el de una nueva técnica y nuevos materiales (he aquí un rasgo de gran coherencia en este artista). Al darnos cuenta de la intimidad comba- 
tiente y gozosa de su trayectoria cuerpo-pintura, no nos sorprende que haya inventado los Atl-colores, las aqua-resinas, la técnica por supresión, como nosotros llamamos a su técnica en blanco y negro. Todo está en la mira de economizar tiempo para captar más rápidamente el tiempo de la intensidad corporal y del espíritu en acción. ¿No es verdad que los Atl-colores pueden ser usados sobre cualquier superficie, a cualquier hora y en el sentido que ojo, mano y deseo quieran darles? Ahorrar el acostumbrado tiempo social del reloj para llegar a un tiempo pequeño en la ejecución que se emparente con el vértigo velocísimo del deseo. Tiempo paciente y gozoso del caminante, tiempo-sin tiempo del deseo pictórico y del deseo como un impulso orgánico y espiritual que inevitablemente tiene que realizarse en un hacer intelectual o artístico se confunden amorosamente en su pintura. Es evidente que todo arte tiene que ver con la duración, pero mucho más el del paisaje, desde su despliegue en tanto que panorama hasta su gestación en el pensamiento del artista. El paisaje está ligado, incluso, a lo que llamamos "el tiempo" en sentido meteorológico, y sufre metamorfosis estrictamente físicas a las que el creador tiene que ceder. En el caso del paisaje, la duración es un lapso de cambio en el que, a velocidad constante, se llevan a cabo metamorfosis estrictamente epifánicas y fisiológicas en ritmos cíclicos: un paisaje cambia varias veces de la noche a la mañana, e igualmente su composición química, lumínica, etc. Imaginemos cuánta riqueza metábolica se despliega tras los nombres espléndidos de "alba", "mañana", "crepúsculo", ligados a la vida de un paisaje, y aún más, a la vida de un paisaje-obra de arte, en que la duración o lapso contable no sólo concierne a las metamorfosis físicas a las que hemos aludido, sino a las que se realizan en la conciencia e inconciencia pictóricas del artista.

Esa concepción del tiempo y la materia fue la que armó a Atl de una nueva técnica; tiempo en los sentidos enfrentando el paisaje real-concreto y tiempo del espiritu que son mucho más difíciles de unificar sobre la tela que al representar animales o plantas, porque hay que sincronizar un orden grande con un orden pequeño del cuerpo considerado individualmente, mientras que un animal o una planta están más cerca del pintor ya que los dos son órdenes pequeños o microcosmos afines en su morfología. Es evidente que nos sentimos más cerca de un caballo o un perro que de un volcán, o por lo menos nos damos cuenta de esa "cercanía" de no ser por las intensidades de su masa, figura y belleza en comparación sorpresiva o meditada con las nuestras. 
Una fisio-estética gozosa; la perspectiva curvilinea (Caminante-pintor y gozo estético)

Dentro de la trayectoria cuerpo-paisaje y en muchos de los escritos de nuestro pintor, sobre todo los dedicados al paisaje mismo, aparece insistentemente la frase "amor por la naturaleza" y alusiones a su magnificencia, a su belleza plástica monumental, a las formas definitivas y definitorias, es decir delimitantes y, sobre todo, al movimiento curvilíneo y a un "centro de gravedad único alrededor del cual gira el universo entero". Todo respira un amor exacerbado por la materia, Atl mismo confiesa tener una tendencia exagerada a representarla, y un gozo enorme por su trabajo. Esto no es extraño para nosotros. Si retomamos el punto en que hablábamos del cuerpo en el caminante y el pintor, tendremos un indicio para crear algunas ideas que nos hablen del principio de ese gozo que, como veremos, es el gozo elemental estético de quien realiza una práctica artística por convicción, vocación y enamoramiento absolutos, que lo satisface hasta con el más arduo problema que dicha práctica le pueda plantear. Pero también es otro tipo de gozo que es, antes que nada, corporal y fisiológico en el sentido de aludir a una unidad con un interior siempre en movimiento. El cuerpo caminante del Dr. Atl es un cuerpo que al desplazarse realiza toda una fiesta orgánica, una euforia ensalzada por la activación vital de la circulación de la sangre, el latir del corazón, la piel que transpira, los músculos hiperoxigenados, la excesiva producción de energía y por lo tanto de calor en todo el cuerpo, y el aumento ininterrumpido de esa euforia que aún encontrándose quien la experimenta en un precipicio de hielo a una temperatura de varios grados bajo cero produce, además del estado eufórico, una sensación de expansión, incluso física, del pensamiento. $Y$ aún más si el caminante está abierto de par en par al encuentro de un paisaje como intensidad, cual si se tratara del encuentro de una persona amada que siempre es la misma y otra a pesar de compartir la vida de todos los días con ella. ¿No hemos experimentado todos nosotros, y me atrevo a decir "sin excepción", esas sensaciones magníficas a las que hemos aludido, con sólo actos tan cotidianos y sencillos como el de jugar, caminar rápidamente, salir de excursión al campo o practicar algún deporte? Estas sencillas y hermosas experiencias nos acercan estrechamente a Atl. Aunque en su momento no nos demos cuenta, gracias a ellas experimentamos la expansión o ilusión de ensanchamiento físico de la conciencia y la caja torácica, es decir, el infinito o llegada inconcebiblemente distante de un posible final, y las posibilidades de un 
elemento simplísimo pero inconmensurable que rige las bases elementales de nuestro sistema visual: la linea curva.

Cuando estamos contentos tendemos a la expansión, a levantar los brazos y el rostro en actitud abrazante hacia arriba, hacia el firmamento, y reímos como reuniendo fuerzas en un eje que vibra en nuestro centro. Cuando estamos contentos difícilmente trazaríamos rectas con los brazos o las piernas en el espacio en actitud de pelea o de agresión, más bien adoptamos una actitud de recogimiento ascendente que traza curvas en el aire, cuyo trayecto puede ser lento o apresurado, aunque en el mundo de Atl este proceso es lento como resultado, debido al procesamiento de la obra. Por un lado tenemos la relación curva-gozo, curva-euforia a una velocidad lenta, y así como la euforia es compatible con la curva, lo es también con el infinito, sentido y entendido a través de la expansión. (La tristeza también casa profundamente con la idea de infinito, pero es centrípeta, nos contrae, por así decir nos "aprieta" hacia dentro. El movimiento que nuestro espíritu realiza bajo el imperio de la tristeza no se transmite impetuosamente al cuerpo, ya que ese sentimiento nos estatifica, nos paraliza cada vez más y no nos permite movernos más allâ de nuestra piel. Es lo que pasa, entre otras cosas, al deprimido que permanece durante varios días bocarriba sobre su cama, mirando sin ver el techo y dando rienda suelta a su cinematografía mental. Nada más lejano del Dr. At1.)

Aunque la curva tienda, más que la recta, a unir sus extremos, por ejemplo en el círculo, y esto implique siempre un posible final o límite, tiene relación directa con la infinitud porque se cierra formando un absoluto, y la fuerza del absoluto o totalidad es una manifestación del infinito. La recta, que también prolifera en la obra de Atl y aleja cada vez más sus extremos en su trayecto de un solo sentido, también puede ser infinita y nos exige pensar y sentir más rápidamente. El ojo y el corazón emplean más tiempo en recorrer una curva que una recta ... Es obvio e inevitable que el Dr. Atl defienda la curva como la línea de la vida y que afirme que "el universo es una rotación de curvas", como si dijera "una rotación de lentitudes", y sostenga que el infinito es la más grande fuerza expansiva de la mente. Esto último no es nada nuevo en boca de Atl en cuanto a historia de la filosofía se refiere, pero subraya enérgicamente la sólida coherencia que alcanzaron los niveles sobrenaturales de la curva, el gozo y la expansión en él como hombre, como artista y como pintor.

¿Cómo no iba a necesitar inventar la perspectiva esférica nuestro personaje? Su vida de caminante y su alegría orgánica y psicológica tenían que conducirlo a implantar la curva como instrumento para mejor devorar 
la totalidad y el infinito tanto dentro de sî como el "infinito físico", el que se enfrenta en lo alto de las montañas al contemplar el nacimiento de la noche o el alba. Estos son elementos que coadyuvan al origen de la fuerza extraordinaria $-\mathrm{y}$ utilizo con toda propiedad y profunda admiración este término- de sus vistas aéreas del Popocatépetl y de otros volcanes. Vemos su acentuación de la riqueza de la curva en sus horizontes, sí, pero también, y quizá con más claridad que en otras zonas de sus cuadros, en sus cielos enormes y esplendorosos. Allí, el azul es manejado curvamente hacia arriba, de la más oscura a la más clara intensidad. Este recurso aumenta la sensación de gran despliegue de fuerzas magnéticas. La idea de infinito que nos produce el azul es terriblemente fuerte y definitiva. Ningún otro color es capaz, quizá, de causarnos esa sensación y columbrarla en nosotros tan pura, cristalina y distantemente como el azul. Acaso el negro se le parezca. Pero el negro nos lleva al infinito sordamente, con una calidez asfixiante, como el interior del hocico de un gran animal o el de la boca del amante hacia el beso, e implica muerte, es decir un momento de cesación del infinito mismo (me refiero. a la muerte como un "tope" momentáneo, aunque después, como sabemos, continúe sus propias maneras de interrumpir la vida). El azul nos puede helar, pero no nos mata como el negro, y esto ya fue una lección de los impresionistas, pintores muy admirados por Atl.

Para Atl, digámoslo familiarmente, "la mesa estaba puesta", ya que el cielo, inmensidad en la que el infinito se nos presenta esencial y poderoso, es azul. Por lo tanto, el poder del azul y el uso de la línea curva, aumentando su intensidad, se emparentan perfectamente. De aquí que líneas arriba sostuviéramos que el sentido de las fuerzas de su mundo se identifica más con lo que va de abajo hacia arriba que con lo que cae. Aunque el sistema curvilíneo de sus paisajes contenga algunas líneas que proyectan y señalan un descenso, provoca siempre un sentido de grandeza, expansión y ascensión explosivas en donde lo único "cayente" y ascendente a la vez, y que surge de dentro de las masas que él pinta, es la luz, elemento que tonifica o fragiliza el cromatismo de su pintura. (Es cierto que esta captación del paisaje le fue reforzada por su visión literalmente aérea del mismo - cuánto tuvo que ver con esto el avión, tanto, que merecería insertarlo más detenidamente en todo este engranaje como impulso mecánico autónomo, pero esto ya no nos concierne por el momento-. Sabemos que perdió una pierna y ya no pudo caminar en las montañas como lo había hecho hasta antes de la erupción del Paricutín).

Tanto sus paisajes en color como en blanco y negro parten de las mismas trilogías y parejas de elementos rectores que señalamos atrás, pero 
el manejo de fuerzas es diferente según la técnica y los materiales elegidos para trabajar, y por sus posibilidades cromáticas o de luz y sombra.

El material elegido fue a veces el color, con gamas frías de azules rigiendo los diversos sentidos, velocidades e intensidades, excepto en algunas obras sobre el Paricutín. En otros paisajes, son la luz y la sombra a partir del blanco y el negro. Por lo tanto, la luz rige la entonación y sustituye el papel de los azules y de toda la gama de sensaciones que los colores nos producen. La intensidad es más pura en los dibujos en blanco y negro del Paricutín, porque no hay color que "nos distraiga"; estamos concentrados en los vaivenes del entrecruzamiento en sí de fuerzas en esta parte de su obra. Allí, Atl parte del negro, descubre la luz sobre el papel con un borrador que levanta la previa capa delgada de carbón que ha extendido sobre la superficie, y a partir de esta técnica por supresión va modelando y entonando la velocidad de las formas de esos paisajes en blanco y negro, los cuales principian en el negro y finalizan en el negro como elemento limitante (con negro realza algunos perfiles de montañas, árboles, piedras y nubes).

\section{Un "premio" de la naturaleza}

Todo lo hasta aqui desarrollado sobre Atl - la fusión dramática de cuerpo-tierra, aire, luz, esfuerzo, la mutua conquista y compenetración amorosa entre caminante-pintor y paisaje, la lucha de fuerzas al parejo entre espíritu y paisaje como trayecto intensivo ascendente, y todo lo que Atl pintó desde antes de 1922, su cuestionamiento de 1933 como pintor que no nació pintor frente a la naturaleza, realidad que él consideraba la más grande y digna de ser representada - se concretó caótica, destructora y creativamente en su vida con el Paricutín, esa larga vida amorosa en común que llevó a cabo con el volcán michoacano casi desde el día del nacimiento de éste. Ese es, quizá, el mayor ejemplo de su compenetración con la naturaleza, ctyyo fruto es la serie espléndida de paisajes dedicados al volcán, y el libro Como nace y crece un volcán, diario poético-científico que a pesar de sus esfuerzos de rigor científico y de observación, es más la obra de alguien acostumbrado al rigor libérrimo de la poesía.

Pareciera que la naturaleza le hubiese ofrecido "tal vez generosamente", como él mismo expresara en sus definiciones sobre el paisaje, este proceso-espectáculo de consagración y "premio" a una larga vida dedicada a ella. $\mathrm{Y}$ no es que seamos moralistas y tratemos de trasponer ingenuamente esta actitud moral a la naturaleza, pero creemos que, como imagen, la del "pre- 
mio" nos ayuda a metaforizar la belleza de ese acto de enfrentamiento imprevisto. Nunca antes Atl había vivido más profundamente la relación caos-destrucción-creación dentro de un panorama de belleza destructora absoluta. Dirá: "Yo me ocupo del Paricutín con un profundo interés obedeciendo solamente a la acción de una fuerza tradicional: gran parte de mi vida la he ocupado en escalar volcanes, en estudiarlos, en dibujarlos, y, de repente, la naturaleza puso a la puerta de mi casa un volcán nuevo. ..".

Los procesos de esfuerzo-desplazamiento y ascensión se invirtieron. El caminante contemplaría y observaría el paisaje en movimiento, tal como el paisaje lo observó y contempló durante años, y también ahora, el volcán y el paisaje realizarían todos los esfuerzos y duraciones que el pintor impusiera; tiempo, fuerza y ascenso estarían determinados por el nacimiento de la montaña. Las formas provenían, como provinieron antes, de la intensidad del hecho en proceso. Fue ver de pronto realizado en el caos y los levantamientos telúricos, el proceso de gestación formal que otrora fuera meramente interior. Fue verlo como proyectado en una gran pantalla celeste, después de haberlo filmado largamente en el corazón y el ojo.

Lo vivido con el paisaje hasta entonces, se realizó dentro de una violencia gigantesca, tanto más cuanto que en el panorama aparecerían nuevos elementos: ruidos de detonaciones, aire enrarecido, arenas asfixiantes y lava y fuego en absoluta prepotencia estético-destructora que comprendía desde su propia luz hasta su inevitable poder para calcinar todo un pueblo. Incandescencia, oscuridad y ruido sustiyeron al azul de los paisajes llenos de aire frío (icuántas metamorfosis tuvo que sufrir el azul para convertirse en fuego!). Los sentidos de expansión y de infinito serían marcados por la destrucción y el poder lumínico de la materia ardiente, ya no por la helada transparencia y la luz del sol horizontal recortante sobre volcanes de actividad extinta, como el Popo o el Ixtla. ${ }^{7}$

\footnotetext{
${ }^{6} \mathrm{Dr}$. Atl, Cómo nace y crece un volcán, México, Stylo, 1959, p.

${ }^{7}$ Un cielo azul no es igual a un cielo invadido por el fuego y el humo. Al analizar la obra pictórica de un autor en su totalidad, en donde aparecen esas diferencias, hay que ver las de tipo formal, cromático, de composición, pero también calibrar, valorar, por así decir, la "personalidad" esencial de cada elemento de ese universo pictórico deniro del coniexto en el que se encuentra; el azui no es el mismo sobre una pared que sobre un cielo; el fuego no es igual en una fogata que brotando del cráter de un volcán, y esto hay que considerarlo unido, claro está, a las intenciones del pintor. Casi siempre los críticos olvidan este aspecto. Es verdad que esto es lo que nos encontramos en un universo antes que nada pictórico, pero es imperativo incluir en el discurso algunas apreciaciones sobre el papel que los elementos juegan en cada realidad, y el nuevo parámetro de velocidades que establecen en relación con los otros elementos de la obra. Aquí aludiríamos a la tan controvertida, rechazada, aceptada, discutida "carga poética" 0 , en el mejor de los casos, poesía, que el crítico debe infundir a su análisis, lo cual querámoslo o no, abre mil posibilides al análisis mismo para continuar una trayectoria creciente en puntos de vista y todogénero de enriquecimientos
} 
La serie de pinturas paricutíneas del Dr. Atl nos incita a meditar sobre las relaciones entre el cuerpo y el caos, el cuerpo frente al caos y el cuerpo que deviene paradójicamente, en cierta manera, el caos mismo a través de la obra de arte. Esa serie nos confirma también que la imaginación se dešboca y renueva verdaderamente sólo ante la catástrofe y el miedo -miedo estético en el caso de Atl-. Su realismo llega a ser tal, que descuella en una exacerbada interpretación y tergiversa las concepciones acostumbradas; es cuando las arenas que rodean al Paricutín devienen un impetuoso remolino verde que danza alrededor del cono sobre un fondo morado intenso, o los varios aspectos nocturnos del mismo volcán, entre los cuales hay uno en que los vapores incandescentes parecen formar un falo enorme rodeado por dos columnas de humo. (En ese momento, el fuego deviene la idea de falo, entra con "nueva figura", con nuevo disfraz en un flujo de intensidades nuevo). Así debió ser aparentemente el espectáculo que Atl tuvo frente a sí, pero es evidente que el desenvolvimiento potentísimo de un CAOS-GERMEN lo abrió de raíz más que nunca hacia la captación de intensidades y de fuerzas en conjunción con el gozo de presenciar el nacimiento de un volcán, el gozo de la visión cromática del mismo y el gozo del acto creativo llevado a cabo en la obra misma.

Todos los elementos, tanto los internos como los exteriores, coadyuban al surgimiento de lo que yo llamo realismo intensivo en su obra. Más que una práctica artística que tenga que ver con la "cosa pintada" desde un punto de vista solo óptico o visual, o visual táctil que insista meramente en los volúmenes con miras a su sola representación, más que eso, tiene que ver con la cosa como intensidad molecular y pictórica, y como elemento que forma parte de un conjunto antónomo en constante movimiento, lo acabamos de vèr, pero no está excento de verse modificado por las fuerzas propias de la cosa o cosas que lo componen. ${ }^{8}$

Las obras de Atl son su vida misma. Nacieron de la liga fortísima, única, indisoluble entre cuerpo, naturaleza y obra de arte, fusión de la euforia corporal y los cambios de intensidad del paisaje, de la alegría de caminar y la belleza violenta que, como él decía, "se echa encima".

De ahí que sus paisajes sean absolutamente incriticables desde una perspectiva crítica que sólo considerara el aspecto formal, de composición o de manejo cromático en sí, o que "hinque los dientes" en los "errores" anatómicos de sus retratos o autorretratos y pierda de vista el conjunto potente de su obra como totalidad. Razones no me han faltado en este artículo para sostenerla y señalar sus defectos técnicos, pero eso no permite

\footnotetext{
${ }^{8}$ Empleo la palabra "cosa" - "res" en latín_ por que es de donde viene la palabra "realismo", "lo que concierne, analiza, se ocupa o preocupa de la cosa".
} 
afirmar que era mal pintor, $o$, refiriéndose a su literatura poética, que era un mal poeta. Es verdad que no fue gran poeta de verso escrito, pero sí un poco a la manera de los santos errantes (como San Francisco). Los santos casi nunca necesitaron de los versos; su caminata interminable es sus versos. Lo que tienen que decir comunica un impulso tal a su propio cuerpo, que no les queda otra que dejar lugares y lugares tras de sí. Su camino es su escritura.

He aquí algunas reflexiones sobre este artista único en la historia del arte mexicano y caso espléndido de coherencia entre cuerpo, poesía y pintura, a quien nunca podrá clasificarse ni dentro del clasicismo, aún tomando en cuenta los desnudos miguelangelescos que pintó, porque la medida como propósito no era de su preferencia; ni del expresionismo, porque no era un subjetivista cuya obra estuviese regida por la expresión de una interioridad violentada y angustiada, sino siempre por el gozo; ni dentro del impresionismo, porque la naturaleza no sólo le interesaba como variación de intensidades lumínicas, y, aún menos, en el surrealismo, porque el mundo del inconsciente le hubiese resultado débil y oscuro como materia de trabajo... 